CNS Spectrums (2017), 22, 203-219. C Cambridge University Press 2017. This is an Open Access article, distributed under the terms of the Creative Commons Attribution licence (http://creativecommons.org/licenses/by/4.0/), which permits unrestricted re-use, distribution, and reproduction in any medium, provided the original work is properly cited.

\title{
Guidelines for the recognition and management of mixed depression
}

\author{
Stephen M. Stahl, ${ }^{1,2,3 * D e b b i ~ A . ~ M o r r i s s e t t e, ~}{ }^{3}$ Gianni Faedda, ${ }^{4,11}$ Maurizio Fava, ${ }^{5}$ \\ Joseph F. Goldberg, ${ }^{6}$ Paul E. Keck, ${ }^{7}$ Yena Lee, ${ }^{8,9}$ Gin Malhi, ${ }^{10}$ Ciro Marangoni, ${ }^{11}$ \\ Susan L. McElroy, ${ }^{7}$ Michael Ostacher, ${ }^{12,13}$ Joshua D. Rosenblat, ${ }^{8,9}$ Eva Solé ${ }^{14}$ \\ Trisha Suppes, ${ }^{12,13}$ Minoru Takeshima, ${ }^{15}$ Michael E. Thase, ${ }^{16}$ Eduard Vieta, ${ }^{14}$ \\ Allan Young, ${ }^{17}$ Mark Zimmerman, ${ }^{18}$ and Roger S. McIntyre ${ }^{8,9}$
}

\footnotetext{
${ }^{1}$ Department of Psychiatry, University of California, San Diego, California, USA

${ }^{2}$ Department of Psychiatry, University of Cambridge, Cambridge, United Kingdom

${ }^{3}$ Neuroscience Education Institute, Carlsbad, California, USA

${ }^{4}$ Lucio Bini Mood Disorders Center, New York, New York, USA

${ }^{5}$ Department of Psychiatry, Massachusetts General Hospital, Boston, Massachusetts, USA

${ }^{6}$ Department of Psychiatry, Icahn School of Medicine at Mount Sinai, New York, New York, USA

${ }^{7}$ Research Institute at the Lindner Center of HOPE, Mason, Ohio, USA

${ }^{8}$ Mood Disorders Psychopharmacology Unit, University Health Network, Toronto, Ontario, Canada

${ }^{9}$ Institute of Medical Science, University of Toronto, Toronto, Ontario, Canada

${ }^{10}$ Department of Psychiatry, University of Sydney, Sydney, Australia

${ }^{11}$ Centro Lucio Bini, Rome, Italy

${ }^{12}$ VA Palo Alto Health Care System, Palo Alto, California, USA

${ }^{13}$ Department of Psychiatry and Behavioral Sciences, Stanford University Medical Center, Stanford, California, USA

${ }^{14}$ Hospital Clinic, Institute of Neuroscience, University of Barcelona, IDIBAPS, CIBERSAM, Barcelona, Catalonia, Spain

${ }^{15}$ Psychiatry Clinic, Sainen, Kanazawa City, Ishikawa Prefecture, Japan

${ }^{16}$ Department of Psychiatry, Perelman School of Medicine, University of Pennsylvania, and the Corporal Michael J. Crescenz Veterans Affairs Medical Center, Philadelphia, Pennsylvania, USA

${ }^{17}$ Department of Psychological Medicine, Kings College, London, United Kingdom

${ }^{18}$ Department of Psychiatry, Rhode Island Hospital, Providence, Rhode Island, USA
}

A significant minority of people presenting with a major depressive episode (MDE) experience co-occurring subsyndromal hypo/manic symptoms. As this presentation may have important prognostic and treatment implications, the DSM-5 codified a new nosological entity, the "mixed features specifier," referring to individuals meeting threshold criteria for an MDE and subthreshold symptoms of (hypo)mania or to individuals with syndromal mania and subthreshold depressive symptoms. The mixed features specifier adds to a growing list of monikers that have been put forward to describe phenotypes characterized by the admixture of depressive and hypomanic symptoms (e.g., mixed depression, depression with mixed features, or depressive mixed states [DMX]). Current treatment guidelines, regulatory approvals, as well the current evidentiary base provide insufficient decision support to practitioners who provide care to individuals presenting with an MDE with mixed features. In addition, all existing psychotropic agents evaluated in mixed patients have largely been confined to patient populations meeting the DSM-IV definition of "mixed states" wherein the co-occurrence of threshold-level mania and threshold-level MDE was required. Toward the aim of assisting clinicians providing care to adults with MDE and mixed features, we have assembled a panel of experts on mood disorders to develop these guidelines on the recognition and treatment of mixed depression, based on the few studies that have focused specifically on DMX as well as decades of cumulated clinical experience.

Received 7 January 2017; Accepted 24 January 2017; First published online 28 February 2017

Key words: Mixed, bipolar, depression, unipolar, guidelines.

* Address correspondence to: Stephen M. Stahl, Department of Psychiatry, University of California-San Diego, Neuroscience Education Institute, 1917 Palomar Oaks Way, Suite 200, Carlsbad, California 92008, USA.

(Email: smstahl@neiglobal.com)

\section{Introduction}

The recent addition of the mixed features specifier in the latest edition of the Diagnostic and Statistical Manual (DSM-5) codifies a new nosological entity characterized by subthreshold hypomanic or manic symptoms 
occurring during depressive episodes of either major depressive disorder (MDD) or bipolar I or bipolar II disorder. ${ }^{1}$ The introduction of the DSM-5 mixed features specifier also reflects a growing consensus that mood disorders may be conceptualized along a spectrum ranging from pure unipolar depression, through an admixture of varying degrees and presentations of depressive and manic symptoms, to pure mania (Figure 1). ${ }^{2-6}$ Perhaps one of the greatest challenges in recognizing the existence of mixed depression or depressive mixed states (DMX) is the question of how to optimize treatment for patients with depression who exhibit concomitant subthreshold features of hypomania or mania. Although there are several guidelines available that provide recommendations for the treatment of unipolar depression, for bipolar depression, and for bipolar mania, there is currently only one treatment guideline that has provided decision support for individuals presenting with a major depressive episode with mixed features (i.e., the Florida Best Practice Psychotherapeutic Medication Guidelines for Adults [2015], available for download at http://www. medicaidmentalhealth.org/_assets/file/Guidelines/Web _2015-Psychotherapeutic\%20Medication\%20Guidelines \%20for\%20Adults_Final_Approved1.pdf). ${ }^{7-19}$ In fact, any treatment guidelines developed prior to the release of the DSM-5 that mention "mixed states" are based on the previous DSM-IV diagnostic criteria that refer to co-occurring full-blown, threshold-level depression with full-blown, threshold-level mania (mixed mania) and simply lump mixed states together with bipolar mania in terms of treatment recommendations. ${ }^{20}$

Since the release of the DSM-5 in 2013, it has been suggested that clinicians follow existing guidelines written for the treatment of MDD or bipolar disorder (BD) without any particular reference to individuals presenting with depressive episodes with mixed (DMX) features. However, not only is DMX different in its clinical presentation compared to an MDE, it is not pathognomonic of either MDD or BD. Toward the aim of filling the gaps between updated diagnostic criteria, the latest research findings, and optimal clinical practice, we have gathered together a panel of experts on mood disorders to develop a set of guidelines for the recognition and treatment of DMX.

The guideline recommendations throughout this article are made in reference to DSM-5 rather than DSM-IV descriptions and criteria. However, the diagnostic criteria warranting a DSM-5 major depressive episode (MDE) with mixed features diagnosis exclude "overlapping symptoms" of irritability, distractibility, insomnia, and psychomotor agitation as defining of the opposite polarity due to the presence of these symptoms in both mania and depression. The exclusion of overlapping symptoms increases the specificity of the diagnosis at the expense of sensitivity and possibly face validity insofar as most individuals presenting with an MDE and mixed features do present with "overlapping symptoms." ${ }^{21-31}$ The potential of DMX being misdiagnosed and treated as pure unipolar depression is far greater than if unipolar depression is misdiagnosed and mistreated as DMX).

\section{Overview and Key Points}

- Not all patients with depression (as part of bipolar disorder or major depressive disorder) should be prescribed an antidepressant.

- All patients who receive antidepressants for an MDE should be monitored for signs of abnormal behavioral activation or psychomotor acceleration.

- The use of antidepressants in MDE patients with mixed features may not alleviate depressive symptoms and may pose a potential hazard for exacerbating subthreshold mania symptoms that accompany depression.

- For an individual presenting with a depressive episode with mixed features, in addition to antidepressant medication, alternative psychotropic agents (e.g., lithium, anticonvulsant mood stabilizers, atypical antipsychotics) with demonstrated efficacy in treating depressive symptoms as part of MDE may be considered.

- You will not know if a depressed patient has (hypo)manic symptoms or a positive family history of bipolar disorder unless you ask! Ask every patient. Every time.

\section{Assessment}

DSM-5 diagnostic criteria for a major depressive episode ${ }^{1}$ (consider an itemized depression screener such as the Quick Inventory Depressive Symptomatology-Self Report or Clinically Useful Depression Outcome Scale)

- EITHER depressed mood OR anhedonia/loss of interest AND four (or more) of the following symptoms:

$>$ Weight/appetite changes

$\triangleright$ Sleep disturbances

$\triangleright$ Psychomotor agitation or retardation

$\triangleright$ Fatigue

$\triangleright$ Worthlessness or guilt

$\triangleright$ Executive dysfunction

$>$ Suicidal ideation or thoughts of death

- May be part of unipolar depression, bipolar II depression, or bipolar I depression 


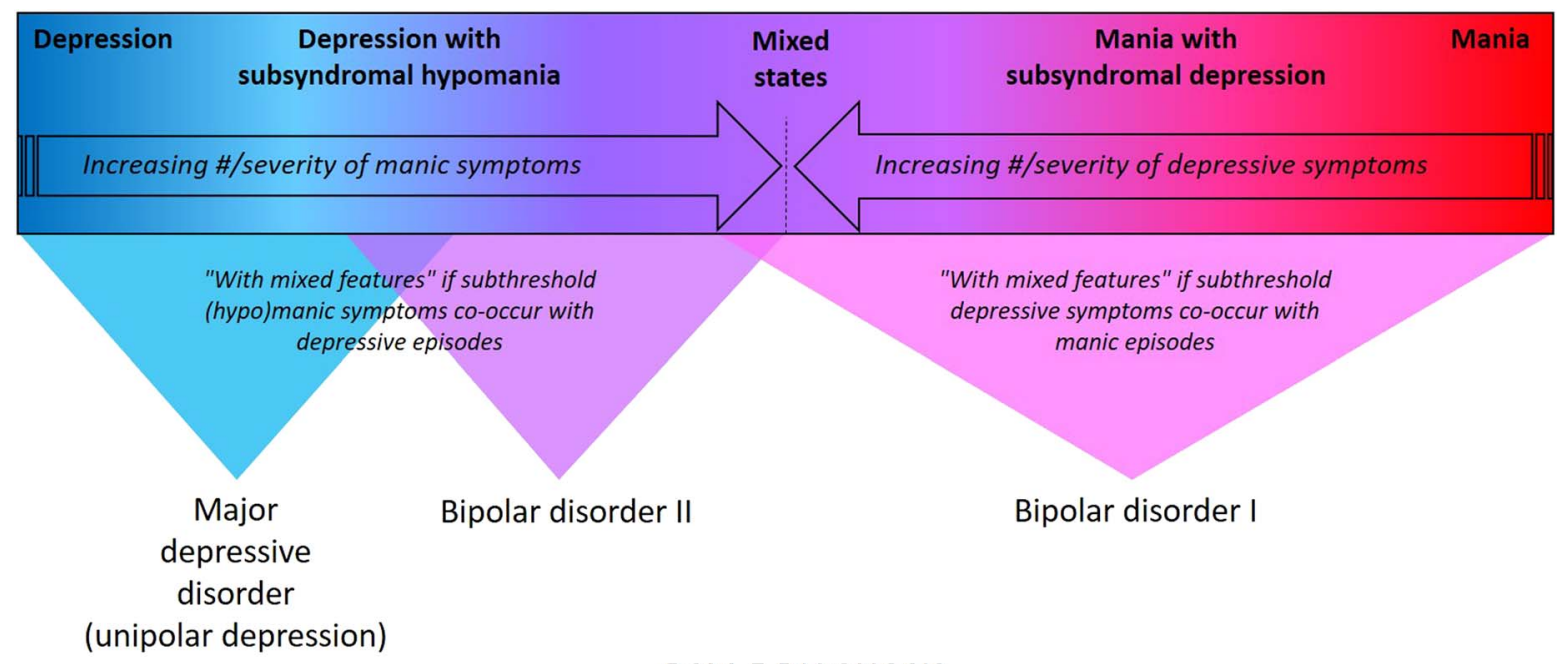

DSM-5 DIAGNOSIS

FIGURE 1. Mood disorders spectrum and DSM-5 diagnosis. Mood disorders can be conceptualized as existing along a spectrum that spans from pure unipolar depression with no intra- or inter-episode symptoms of (hypo)mania all the way to threshold level mania.

\section{DSM-5 diagnostic criteria for the mixed features specifier ${ }^{7}$}

- Full criteria for a major depressive episode and at least three of the following (hypo)manic symptoms during the majority of days of the current or most recent depressive episode:

$>$ Elevated, expansive mood

$>$ Inflated self-esteem or grandiosity

$>$ More talkative than usual or pressure to keep talking

$>$ Flight of ideas or subjective experience that thoughts are racing

$>$ Increase in energy or goal-directed activity

$>$ Increased or excessive involvement in activities that have a high potential for painful consequences

$>$ Decreased need for sleep (to be contrasted with insomnia)

- May be part of unipolar depression, bipolar II depression, or bipolar I depression

\section{Non DSM-5 diagnostic criteria for mixed depression} (overlapping symptoms) ${ }^{2,21-23,25,29}$

- Controversy exists as to whether the symptoms of DMX are fully captured by the DSM-5 diagnostic criteria, as well as the extent to which DMX symptoms can be differentiated from comorbid disorders or other conditions, including borderline personality disorder, posttraumatic stress disorder, substance use disorders, and attention deficit hyperactivity disorder ${ }^{29,32}$

- Alternative diagnostic criteria have been proposed and focus on the most common symptoms seen in patients with DMX, including:

$>$ Irritability
$>$ Anxiety

$>$ Distractibility

$>$ Psychomotor agitation

$>$ Racing/crowded thoughts

$>$ Initial and middle insomnia

$>$ Indecisiveness

$>$ Anger

$>$ Increased talkativeness

$\triangleright$ Emotional lability/tearfulness

$>$ Inner tension

$>$ Rumination

$>$ Initial or middle insomnia

$>$ Impulsivity

$>$ Risky behaviors

- These alternative diagnostic criteria for DMX also stress how critical it is to assess the patient for any family history of bipolar spectrum disorders: ${ }^{33-35}$

$>$ Always inquire about family history of bipolar symptoms or ANY symptoms of (hypo)mania in patients presenting with a major depressive episode

$>$ Inquire about common bipolar comorbidities (e.g., migraine, anxiety disorders, substance abuse, obesity, binge eating, ADHD). Although these comorbidities are observed in both BD and MDD populations, data suggest that patients with BD (especially those with BDII and pediatric populations) are more likely to be affected ${ }^{17,36-39}$

\section{Differential Diagnosis}

- The prognosis for depression with cooccurring subthreshold hypomania (DMX) is much worse than for pure unipolar depression or bipolar depression without mixed features ${ }^{26,40}$ 
- A significant minority (about 13-20\%) of individuals with unipolar DMX will eventually meet diagnostic criteria for bipolar I or bipolar II disorder

- In order to avoid treatments that could worsen symptoms of hypo/mania in MDE patients with mixed features (e.g., antidepressant monotherapy), to prevent the development of resistance to appropriate treatments, and to avert treatment-emergent affective switch (TEAS), it is essential that DMX be distinguished from pure unipolar depression as early as possible ${ }^{40-45}$

- A key differential diagnostic issue is unipolar depression with borderline personality disorder versus DMX. Most of the correlates listed below are also correlates of unipolar depression with borderline personality disorder

- MDD with active substance use disorders could inflate rates of false-positive detection of hypo/mania symptoms and requires a careful longitudinal history $^{46}$

- DMX has been associated with:

$\gg$ Family history of bipolar spectrum disorders

$\triangleright$ Suicidality

$\triangleright$ Antidepressant-induced mania

$\triangleright$ Rapid cycling

$>$ Young age of onset

$\triangleright$ Long duration of illness

$\triangleright$ Poor prognosis

$>$ Severe depression

$\triangleright$ Antidepressant resistance

$>$ Females

$\triangleright$ Comorbid anxiety

$\triangleright$ Comorbid substance-use disorder (SUD)

$>$ Impulse control disorders

- There are several assessment tools available to aid in the recognition of subthreshold hypomanic symptoms, including:

$>$ Bipolar Depression Rating Scale (BDRS) ${ }^{47}$

$\odot$ Clinician-administered assessment of current symptoms

$\triangleright$ Hypomania Interview Guide (HIG) ${ }^{48,49}$

$\odot$ Clinician-administered assessment of current symptoms

$\triangleright$ Mini International Neuropsychiatric Interview (M. I.N.I. $)^{50}$

$\odot$ Patient self-report assessing current (hypo) manic symptoms

$\triangleright$ Clinically Useful Depression Outcome Scale with DSM-5 Mixed (CUDOS-M) ${ }^{51}$

$\odot$ Patient self-report assessing current (hypo) manic symptoms

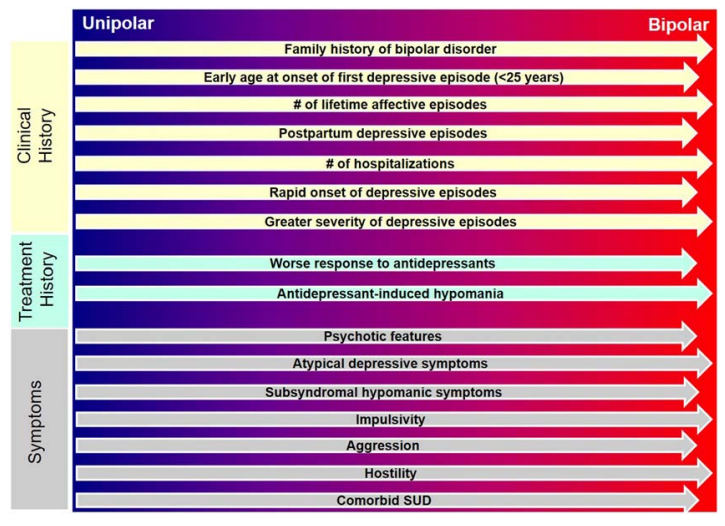

FIGURE 2. The probabilistic approach to differential diagnosis. Numerous factors, including early age at onset of first depressive episode, seasonality, antidepressant-induced (hypo)mania, and impulsivity, while not diagnostic of bipolar depression, are less common in pure unipolar depression compared to bipolar spectrum disorders. Moreover, the presence of psychotic features and extensive family history of psychopathology are additional probabilistic factors for BD. Patterns of comorbidity can also be evaluated as substance-use disorders, and several medical disorders (e.g., migraine and metabolic disturbances) are more common in BD when compared to MDD. Although the presence of any of these probabilistic qualities is not pathognomic, accumulation of these factors should alert clinicians to the possibility that their patient may lie along the bipolar spectrum, either with mixed depression or with bipolar depression.

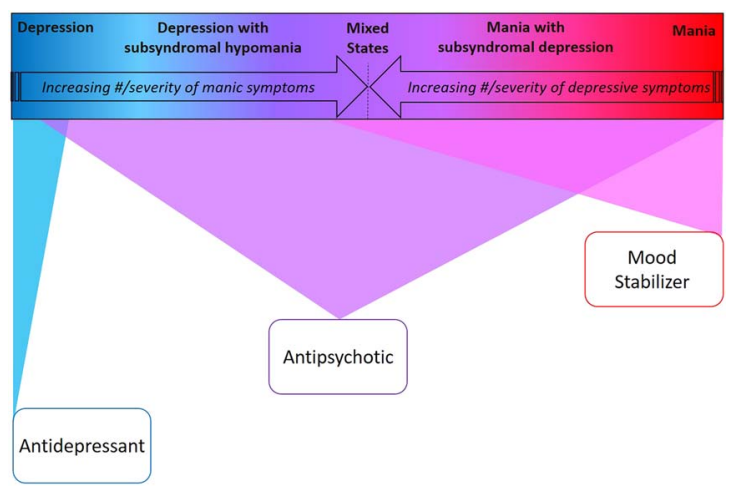

FIGURE 3. Bipolar spectrum-based first-line monotherapy treatment recommendations.

$\triangleright$ Hypomania Checklist $\left(\right.$ HCL-32) ${ }^{33,52}$

$\odot$ Patient self-report that screens for lifetime (hypo)manic symptoms-this does not assess mixed episodes, and has not been suggested to do so

$\triangleright$ Mood Disorder Questionnaire (MDQ) $)^{53}$

$\odot$ Patient self-report that screens for lifetime (hypo)manic symptoms

$\triangleright$ Altman Mania Rating Scale ${ }^{54}$

$\odot$ Patient self-report assessing current (hypo) manic symptoms 


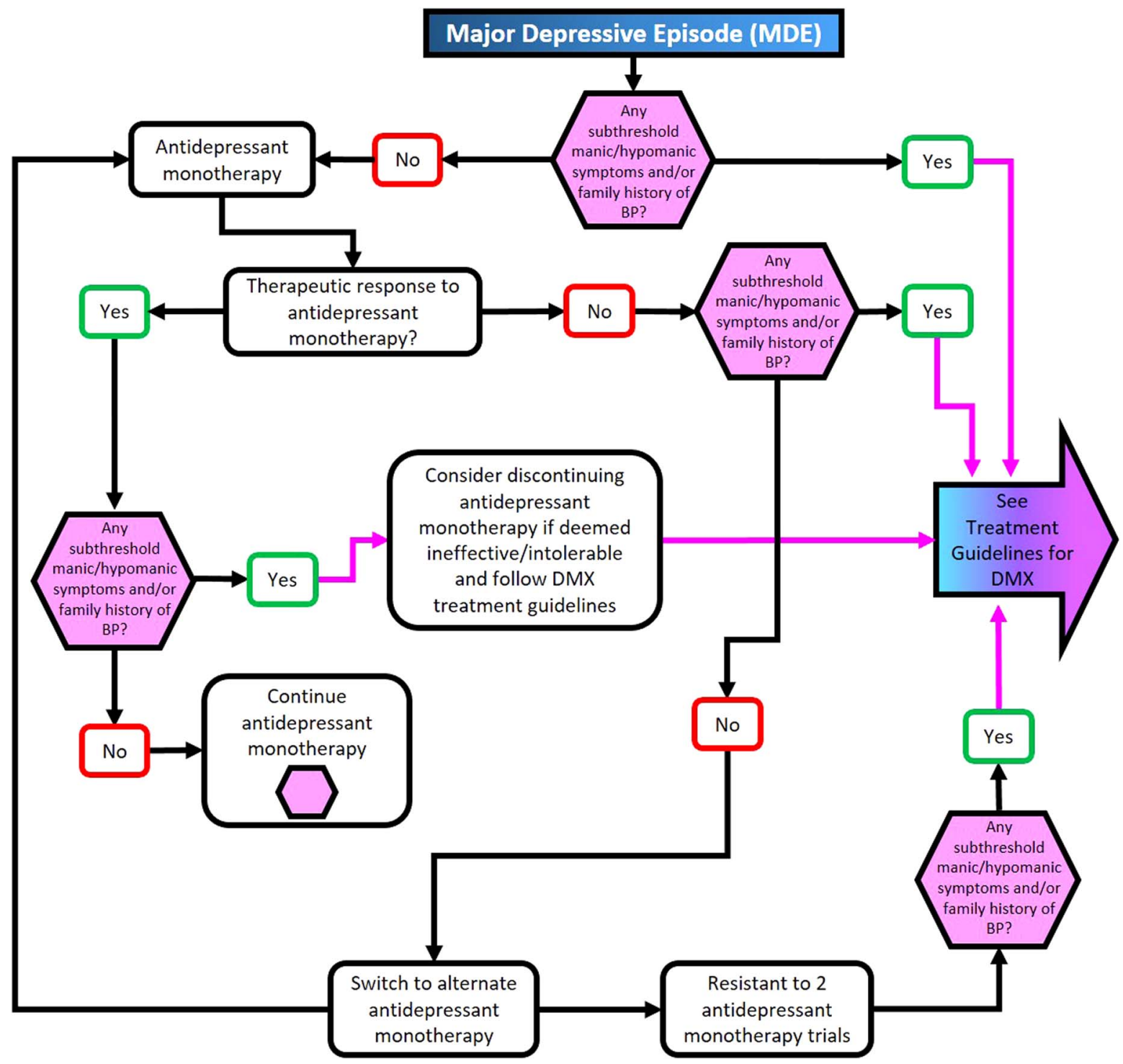

FIGURE 4. Treatment algorithm for major depressive episode without mixed features.

- Patient self-report that screens for "bipolar spectrum disorder" (which includes bipolar I and bipolar II), and the "probabilistic" approach may help to identify patients who are more likely to have a bipolar spectrum disorder rather than pure unipolar depression (Figure 2)

$\triangleright$ The same factors that indicate bipolarity are also evident in patients with DMX

- Rule out comorbid conditions that phenotypically overlap with mixed features and/or secondary causes of (hypo)mania, but keep in mind that some secondary causes (e.g., substance use) could be more frequent among individuals with bipolar than unipolar disorder $\triangleright$ Drug and/or alcohol misuse

$\odot$ If comorbid, the mood state will generally precede and significantly outlast the state induced by intoxication or withdrawal, and a diagnosis of bipolar disorder can be made

$\triangleright$ Certain medications

$\odot$ e.g., L-dopa and corticosteroids, stimulants

$>$ Organic conditions

$\odot$ Most likely in older patients

$\triangleright$ Caffeine use

$\triangleright$ Infections (HIV, syphilis, other)

$\triangleright$ Multiple sclerosis

$\triangleright$ Traumatic brain injury (TBI), brain lesion(s) involving subcortical or cortical areas

$>$ Thyroid disease

$\triangleright$ Disruptive behavior disorders (CD, ODD) 


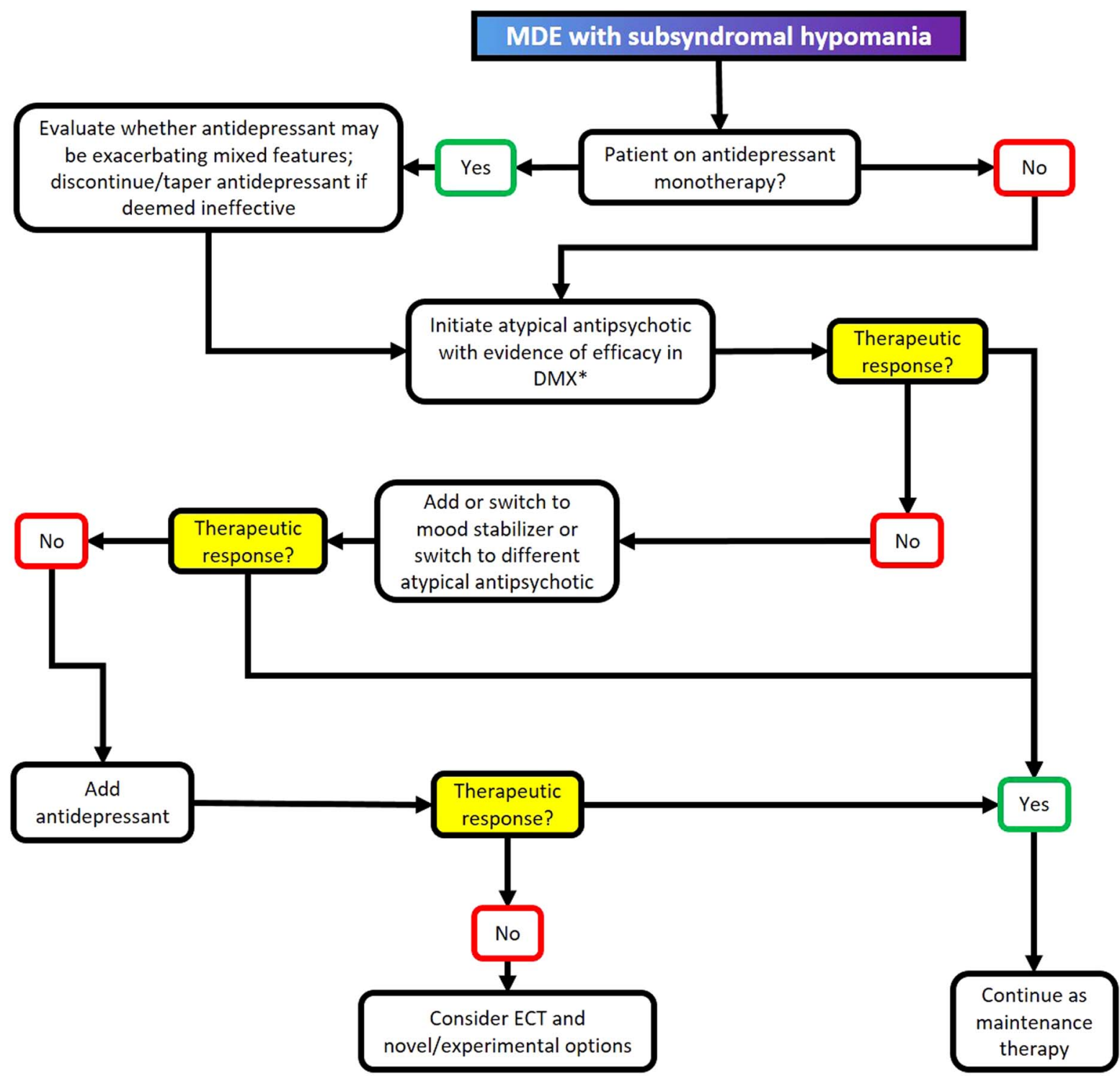

*Asenapine, lurasidone, olanzapine, quetiapine, and ziprasidone have each shown some efficacy in treating DMX

FIGURE 5. Treatment algorithm for major depressive episode with mixed features (DMX).

$>$ Cyclothymic temperament, novelty seeking, narcissistic and borderline personality disorders

$>$ Agitated or anxious depression

$\odot$ It has been proposed that agitated depression (a major depressive episode with psychomotor agitation) is a form of mixed depression because it often occurs along with other symptoms of hypomania ${ }^{22,27,55}$

\section{Baseline Medical History and Laboratory}

\section{Parameters ${ }^{11,56}$}

- Medical history

- Smoking history
- Cardiometabolic family history

- Waist circumference and/or BMI

- Blood pressure

- Complete blood count (CBC)

- Electrolytes, urea, and creatinine (EUC)

- Urine toxicology for substance use

- Fasting glucose

- Fasting lipid profile (TC, vLDL, LDL, HDL, TG)

- Liver enzymes

- Hepatitis A, B, C; syphilis testing in patients deemed at risk

- Estimated glomerular filtration rate

- Platelets

- Thyroid-stimulating hormone

- Serum bilirubin 


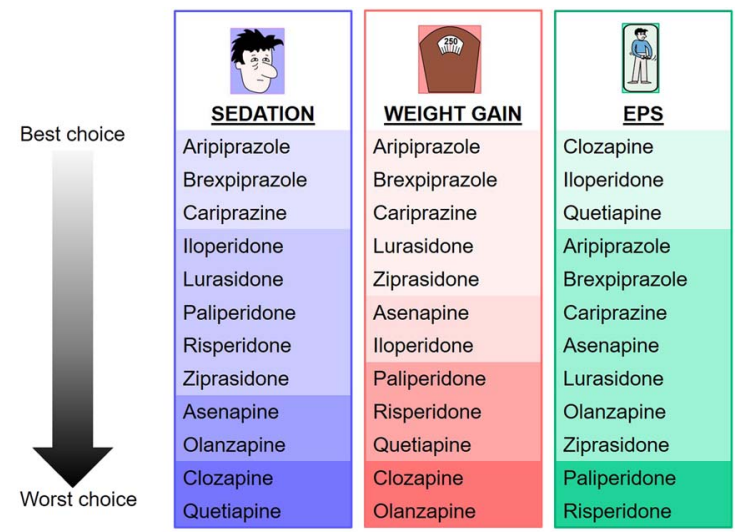

Patients on atypical antipsychotics should be regularly monitored for side effects, including BMI FIGURE 6. Relative tolerability of atypical antipsychotics.

- Electrocardiogram (>40 years or if indicated)

- Prolactin (if relevant)

- Pregnancy test (if relevant)

- Contraceptive use (if relevant)

\section{Treatment}

\section{Initial treatment}

- Antidepressant monotherapy should probably NOT be utilized for patients with mixed depression of any type (unipolar, BP II, or BP I), given persisting doubts about the relative efficacy of standard antidepressants in treating bipolar disorders and their potential to destabilize mood ${ }^{7,8,11,12,25,32,57-68}$

$>$ It is critical that patients presenting with a major depressive episode be assessed for the presence of any symptoms of (hypo)mania and family history of mood disorder, including bipolar disorder, before initiating treatment

$>$ Patients with mixed depression should be monitored regularly for the emergence or worsening of (hypo)mania and suicidality

$>$ Tricyclic antidepressants (TCAs) and serotoninnorepinephrine reuptake inhibitors (SNRIs) may carry the highest risk of causing a treatmentemergent affective switch, ${ }^{11,17,30,62,63,69-73}$ while bupropion and some selective serotonin reuptake inhibitors (SSRIs) may have a lower risk of affective switch

$>$ There is some evidence for the adjunctive use of monoamine oxidase inhibitors in the treatment of bipolar depression ${ }^{74,75}$

$>$ For symptomatic patients with mixed depression, antidepressant monotherapy should generally be tapered and discontinued. Clinicians should carefully assess whether mixed features may be exacerbated by antidepressant monotherapies; in
TABLE 1. Recommendations for acute pharmacological treatment of mixed depression ${ }^{\text {a }}$

$\begin{array}{ll}\text { First-line } & \text { Monotherapy: lurasidone, asenapine, quetiapine, } \\ \text { quetiapine XR, aripiprazole, ziprasidone } & \text { Monotherapy: lamotrigine, valproate, lithium, cariprazine, } \\ \text { olanzapine } & \\ \text { Lecond-line } & \text { ithium, lamotrigine, or valproate + atypical } \\ \text { antipsychotic } & \text { Lithium + valproate } \\ \text { Lithium or valproate + lamotrigine } \\ \text { Olanzapine + fluoxetine } \\ \text { Monotherapy: carbamazepine } \\ \text { Lithium + carbamazepine } \\ \text { Lithium + pramipexole } \\ \text { ECT } \\ \text { Lithium or lamotrigine or valproate or atypical } \\ \text { antipsychotic + bupropion } \\ \text { Lithium or lamotrigine or valproate or atypical } \\ \text { antipsychotic + SSRI } \\ \text { Lithium or lamotrigine or valproate or atypical } \\ \text { antipsychotic + MA0I } \\ \text { Adjunctive modafinil, armodafinil, pramipexole } \\ \text { Adjunctive folic acid, inositol, ketamine, N-acetyl } \\ \text { cysteine, omega-3 fatty acids, ramelteon, or celecoxib } \\ \text { Monotherapy: antidepressants } \\ \text { Monotherapy: topiramate } \\ \text { Carbamazepine + olanzapine or risperidone } \\ \text { GENERALLY NOT }\end{array}$

such instances, consideration should be given either to augmentation with an atypical antipsychotic or antimanic mood stabilizer (e.g., lithium, divalproex, carbamazepine) or else tapering and discontinuing antidepressants altogether if deemed ineffective

- There are currently no psychotropic agents that are FDA- or EMA-approved for the treatment of depression with mixed features

- First-generation antipsychotics and sedatives (benzodiazepines, hypnotics) have been used successfully in the treatment of depressive mixed states

- Atypical antipsychotics (including asenapine, ${ }^{76,77}$ lurasidone ${ }^{78,79}$ olanzapine ${ }^{80}$ quetiapine,${ }^{81}$ and ziprasidone $^{82}$ ) are the only psychotropic agents that have been specifically tested (and shown some efficacy) for the treatment of depression with mixed features

$>$ Not all atypical antipsychotics have demonstrated efficacy in bipolar depression (e.g., Lombardo et al., 2009 ${ }^{83}$ ). Caution is therefore warranted when extrapolating to DMX from outcome studies in frank bipolar disorder. Moreover, these studies did not enroll subjects according to the DSM-5 definition of mixed features

$>$ Cariprazine and aripiprazole have also both shown some efficacy in improving both manic and depressive symptoms ${ }^{84,85}$

$>$ The efficacy of the atypical antipsychotics listed above is suggested largely based on post-hoc 
TABLE 2. Dosing recommendations for pharmacotherapy of mixed depression

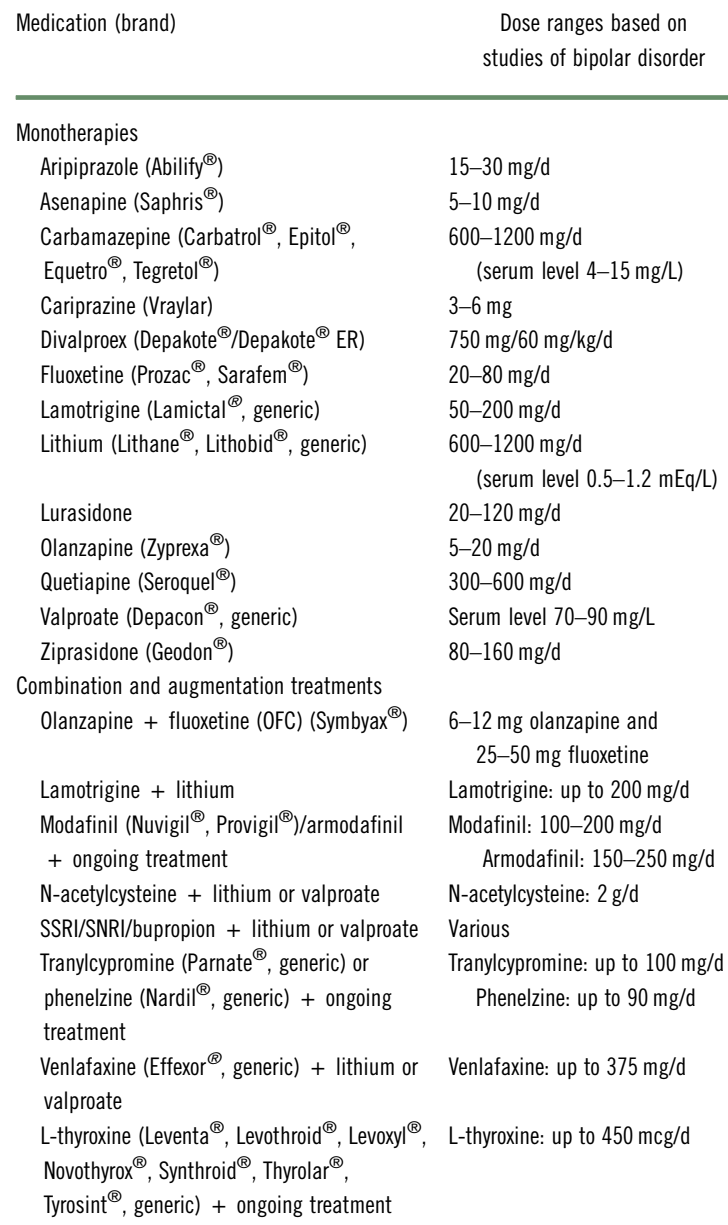

analyses of mixed mania in BDI (i.e., DMX with severe manic symptoms)

$>$ Dose ranges of the atypical antipsychotics suggested in Table 1 may be too strongly sedative for mild to moderate DMX

- No mood stabilizer (lithium and divalproex) is actually approved for use in depression of any kind (unipolar, mixed, bipolar), ${ }^{86}$ except lamotrigine, which is approved for maintenance treatment in bipolar I disorder ${ }^{9,11,14,71}$

$>$ Lithium has traditionally been considered an effective antidepressant treatment augmentation strategy, and often very low doses of lithium can be effective for selected patients

$>$ Lithium is well-known for its anti-suicide, antiaggression, anti-cycling, and antimanic effects. However, lithium also may yield less favorable effects as compared to divalproex in bipolar mixed states. ${ }^{87}$ The efficacy of lithium in bipolar depression and especially mixed depression has not been adequately investigated
Patients failing to respond to monotherapy and continuing to experience subthreshold symptoms or relapses

- The treatment of DMX may require a combination of medications ${ }^{15,18,60,74,88}$

$>$ Combinations with potential efficacy in DMX:

$\odot$ Atypical antipsychotic $+\operatorname{mood}$ stabilizer

$\odot$ Atypical antipsychotic + antidepressant

$\odot$ Olanzapine/fluoxetine combination in particular (caution in overweight or obese patients and those with metabolic dysregulation)

$\odot$ Mood stabilizer + antidepressant

$>$ If an antidepressant is prescribed for DMX, it should be used in conjunction with a moodstabilizing agent (atypical antipsychotic or mood stabilizer); however, it is questionable whether adding an antidepressant to a mood stabilizer or atypical antipsychotic has therapeutic benefit in bipolar disorder patients ${ }^{89}$

$\triangleright$ (Hypo)manic symptoms, irritability, dysphoric mood, and insomnia can deteriorate or develop during antidepressant treatment even in conjunction with mood-stabilizing agents ${ }^{89,90}$

$>$ The role of antidepressants in long-term treatment is controversial and not established by controlled trials in DMX, but they may be used effectively in a small minority of patients in the long term, ${ }^{11}$ particularly if there is a robust initial response or remission without signs of $\operatorname{mood}$ destabilization $^{91}$

$\triangleright$ The combination of olanzapine or risperidone with carbamazepine is not recommended due to potent pharmacokinetic induction of cytochrome P450 enzymes by carbamazepine ${ }^{15}$

- The use of additional short-term medication (e.g., benzodiazepines) may be necessary when an acute stressor is imminent or present, early symptoms of relapse (especially insomnia) occur, or anxiety becomes prominent

- Addition of hypnotics for the treatment of insomnia unresponsive to mood disorder medications may be helpful/necessary

- Higher doses of the long-term treatments may also be effective, thus avoiding the need for additional medications

- Ensure adequate doses of medicines and that serum levels of lithium and valproate are within the therapeutic range

- Address use of alcohol or illicit psychoactive substances that can destabilize mood

- Address current stressors; consider psychosocial interventions in general, particularly those targeting lifestyle/daily rhythms, e.g., interpersonal social rhythm therapy (IPSRT) 
TABLE 3. Notable side effects associated with mood stabilizers

\begin{tabular}{|c|c|}
\hline Lithium & $\begin{array}{l}\text { - Lithium toxicity; toxic levels are near therapeutic levels; signs } \\
\text { of toxicity include tremor, ataxia, diarrhea, vomiting, sedation } \\
\text { - Renal impairment (interstitial nephritis) } \\
\text { - Nephrogenic diabetes insipidus } \\
\text { - Arrhythmia, cardiovascular changes, sick sinus syndrome, } \\
\text { bradycardia, hypotension } \\
\text { - T-wave flattening and inversion } \\
\text { - Dysarthria, delirium, memory problems } \\
\text { - Nausea } \\
\text { - Weight gain }\end{array}$ \\
\hline Valproate & $\begin{array}{l}\text { - Tachycardia or bradycardia } \\
\text { - Rare hepatotoxicity with liver failure } \\
\text { - Rare pancreatitis, sometimes fatal } \\
\text { - Rare but serious skin condition known as "drug reaction with } \\
\quad \text { eosinophilia" (DRESS) } \\
\text { - Sedation, dose-dependent tremor, dizziness } \\
\text { - Abdominal pain, nausea, vomiting, diarrhea, reduced } \\
\text { appetite, constipation, dyspepsia, weight gain } \\
\text { - Ataxia, asthenia, headache }\end{array}$ \\
\hline Carbamazepine & $\begin{array}{l}\text { - Rare aplastic anemia, agranulocytosis (unusual bleeding or } \\
\text { bruising, mouth sores, infections, fever, sore throat) } \\
\text { - Rare severe dermatologic reactions (purpura, Stevens- } \\
\text { Johnson syndrome) } \\
\text { - Rare cardiac problems } \\
\text { - Rare induction of psychosis or mania } \\
\text { - SIADH (syndrome of inappropriate antidiuretic hormone } \\
\text { - Secretion) with hyponatremia } \\
\text { - Sedation, dizziness, unsteadiness, confusion } \\
\text { - Nausea, vomiting, constipation, dry mouth } \\
\text { - Blurred vision } \\
\text { - Benign leukopenia (transient; in up to } 10 \% \text { ) } \\
\text { - Rash }\end{array}$ \\
\hline Lamotrigine & $\begin{array}{l}\text { - Rare serious rash (risk may be greater in pediatric patients but } \\
\text { still rare) } \\
\text { - Rare multi-organ failure associated with Stevens-Johnson } \\
\text { syndrome, toxic epidermal necrolysis, or drug hypersensitivity } \\
\text { syndrome } \\
\text { - Rare blood dyscrasias } \\
\text { - Rare aseptic meningitis } \\
\text { - Benign rash (approximately 10\%) } \\
\text { - Dose-dependent: blurred or double vision, dizziness, ataxia } \\
\text { - Sedation, headache, tremor, insomnia, poor coordination, } \\
\text { fatigue } \\
\text { - Nausea (dose-dependent), vomiting, dyspepsia, rhinitis }\end{array}$ \\
\hline
\end{tabular}

- If the patient fails to respond to optimization of longterm treatment, consider augmentation or change of treatment ${ }^{9,11,12,17}$

$\triangleright$ There are some limited data supporting the adjunctive use of L-thyroxine, ${ }^{92,93} \mathrm{~N}$-acetyl-cysteine (NAC), ${ }^{94,95}$ omega-3 fatty acids, ${ }^{96}$ ramelteon, ${ }^{97}$
TABLE 4. Longitudinal monitoring according to treatment

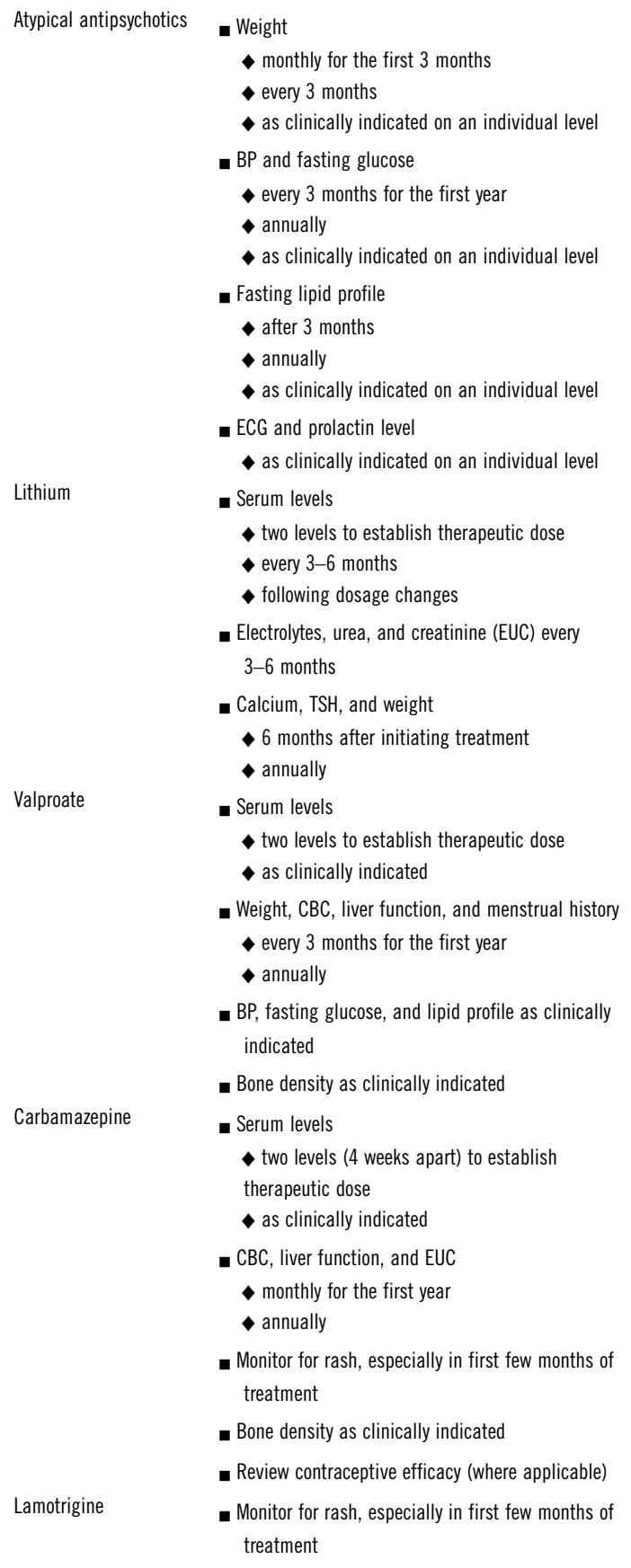

celecoxib, ${ }^{98}$ modafinil, ${ }^{99,100}$ inositol, ${ }^{101,102}$ ketamine, ${ }^{103,104}$ and pramipexole ${ }^{105}$ in the treatment of bipolar depression

- Consider electroconvulsive therapy (ECT) for patients with high suicidal risk, psychosis, severe depression during pregnancy, or life-threatening inanition. Consider simplifying preexisting polypharmacy, reducing drug-to-drug interactions; might lead to changes in seizure thresholds ${ }^{11,25}$ 
- Transcranial magnetic stimulation (TMS) may also have some efficacy in treating mixed depression; however, this supposition is based on "off-label" data from preliminary trials in bipolar depression; attempt TMS only after other options have been tried ${ }^{74}$

\section{Maintenance treatment ${ }^{11,17,71,74,106}$}

- In an individual patient, if one of the recommended acute treatments led to prompt remission from the most recent mixed depressive episode, this may be considered evidence in favor of its long-term use as monotherapy

- The preferred strategy is for continuous rather than intermittent treatment with oral medication to prevent new episodes

- Without active acceptance of the need for long-term treatment, adherence may be poor; consider offering enhanced psychological and social support

- Consistent outpatient follow-up is necessary

- Long-term treatment is indefinite for the prevention of new episodes and to achieve adequate inter-episode control of residual or chronic mood symptoms

- Because of the high risk of relapse and the apparent progression to more frequent episodes, long-term treatment with appropriate medication is advocated from as early in the illness course as is acceptable to a patient and his or her family

- Remain vigilant to conversion to bipolar disorder of patients whose index episode is diagnosed as unipolar DMX

- In the absence of convincing evidence in favor of longterm treatment with antidepressants, the usual policy should be eventual discontinuation, although a small minority of patients have a robust initial antidepressant response and appear to do well on long-term combination treatment that includes an antidepressant ${ }^{89}$

\section{Safety monitoring ${ }^{56}$}

- Suicide is the main serious safety concern in this population, and an individualized approach is necessary depending on clinical variables, social support, and preexisting suicide risk factors

- Take all possible steps to protect and improve the physical health of patients in your care through active screening and treatment of risk factors or declared disease

- Higher morbidity and mortality have been reported in bipolar patients, even before treatment with psychotropic agents was initiated. It is of growing concern that many of the long-term treatments that appear to be required for mixed depression may add to the burden of physical disease

- In addition to baseline laboratory measurements, patients should be monitored continually for the development of adverse events specific to the treatment(s) utilized

- The risk of tardive dyskinesia is significantly increased with the use of antipsychotics and should be monitored for regularly

\section{Discontinuation of treatments ${ }^{9,11,15}$}

- Following discontinuation of medicines, the risk of relapse remains, even after years of sustained remission; accordingly, if considered, it should be accompanied by an informed assessment of the potential costs and dangers

- Discontinuation of any long-term medication should normally be tapered over at least two weeks and preferably longer. Early relapse to mania in bipolar disorder patients is a risk of abrupt lithium discontinuation. Clinical monitoring during treatment withdrawal is desirable

- When a patient has accepted treatment for several years and remains very well, he or she should be strongly advised to continue indefinitely, as the risk of relapse remains high

\section{Children and adolescents ${ }^{12,16,17,34,43,56,61,70,107,108}$}

- The clinical features of childhood mood disorders often differ from those in adults

- Child and adolescent mood disorders are often comorbid with attention deficit and conduct disorders ${ }^{109}$

- Mixed depression is especially common in children and adolescents ${ }^{40,110}$

- The risk of antidepressant-induced suicidality may be highest in the pediatric population due to the presence of mixed features ${ }^{43,57,59,70,108}$

$\triangleright$ Children and adolescents presenting with major depression should be screened and monitored for any (hypo)manic symptoms, suicidality, and family history of mood disorders

$\triangleright$ Antidepressant monotherapy should be avoided in children and adolescents until any presence of (hypo)mania or positive family history of bipolar spectrum disorder is ruled out

- With the exception of fluoxetine, the evidence for efficacy of antidepressants in treating major depressive disorder in the pediatric population is not robust ${ }^{111}$

- Venlafaxine may have the highest risk of increasing suicidality in children and adolescents ${ }^{111}$

\section{Women of child-bearing potential $\left.\right|^{11,17,56}$}

- The postpartum period is a time of very high risk of relapse or recurrence into severe illness in women with mood disorders. Vigilance and close monitoring 
during the perinatal period is essential, and effective prophylactic treatment should be considered

- In pregnancy, there is a risk of teratogenicity from a number of medications used in all phases of treatment. Higher teratogenic risks appear to be associated with certain anticonvulsants (notably, valproate and carbamazepine). Lithium has also been associated with teratogenicity, although prospective studies suggest that the risk is lower than originally described. The lowest risks appear to be associated with the antipsychotics. However, risks for new compounds are usually unknown and always justify caution

- Many psychotropics can cause symptoms in neonates (including discontinuation effects from, e.g., antipsychotics, SSRIs). Neonates should be monitored for possible adverse effects following birth. Long-term effects on cognitive development have been reported with exposure to valproate in pregnancy

- However, optimization of maternal mental health remains a key determinant of pregnancy outcomes; thus, effective treatment of the mother must be carefully weighed against potential risks to the neonate $\mathrm{e}^{112}$

- Discontinuation or switching medications risks destabilizing mood and precipitating relapse. Any risk putatively associated with the use of medications should be considered in the context of the relatively high age-related background risk for congenital malformations and spontaneous abortion in the general population

- If a mother takes medication and breastfeeds, the infant should be monitored for possible adverse effects

- Medications with a high risk in pregnancy such as valproate or carbamazepine should not be used routinely if there is a significant likelihood of pregnancy

\section{Enhanced care c,11,12,25 $^{9}$}

- Make use of evidence to address poor insight, the seriousness of the illness, reluctance to give up the experience of hypo(mania), the risk of relapse, and the benefit of therapeutic engagement

- While respecting patient preferences, education about the illness should emphasize the long-term need for medicines

- Help the patient, family members, and significant others recognize the signs and symptoms of mixed depressive episodes for early treatment; family psychoeducation may improve treatment outcomes

- Psychosocial interventions enhance care, which can increase adherence and reduce the risk of relapse

- A large and comprehensive program of psychoeducation may be superior to an equivalent time spent in nonspecific talking therapy
- Interpersonal and family therapy as well as cognitive behavioral therapy may be beneficial

- Group psychoeducation may also be more effective than cognitive behavioral therapy for some patients

- Internet-based psychosocial interventions may be helpful and hold promise, particularly with respect to accessibility

- A consistent long-term flexible alliance among the patient, the patient's family, and one effective clinician is the ideal arrangement for outpatient care in patients whose condition has been effectively stabilized. Patients' relatives should feel comfortable contacting the clinician to report escalations of symptoms or other emergencies

- Known tolerability of available medicines should guide prescribing:

$\triangleright$ Inform patients about possible side effects and monitor their possible emergence

$\triangleright$ Make side effect reduction a priority by lowering the dose, by employing different scheduling (e.g., prescribing all sedative medicines at bed time), or by using alternative formulations

$>$ Some patients with mixed depression may require or tolerate lower doses of mood-stabilizing drugs than those used for threshold-level mania

\section{Disclosures}

Stephen M. Stahl has served as a consultant to Acadia, Allergan, Arbor Pharmaceuticals, Avanir, Axovant, Axsome, Biogen Celgene, Forest, Forum, Genomind, Innovative Science Solications, Jazz, Lundbeck, Merck, Otsuka, PamLabs, Pierre Fabre, Reviva, Servier, Shire, Spout, Sunovion, Takeda, Teva, Tonix, and Vanda; and he is board member of Genomind. He has served on speakers bureaus for Forum, Lundbeck, Otsuka, Servier, Sunovion, and Takeda. He has received research and/or grant support from Arcadia, Actavis, Alkermes, Arbor Pharmaceuticals, Avanir, Axovant, Biogen, Celegen, Eli Lilly, Forest, Forum, Jazz, Lundbeck, Merck, Otsuka, Reviva, Servier, Shire, Sprout, Sunovion, Takeda, Teva, Tonix and Vanda.

Debbi Morrissette has nothing to disclose.

Gianni Faedda has the following disclosure. Manhattan Behavioral Medicine: owner and principal investigator in clinical trials site.

Maurizio Fava has the following disclosures. Research Support: Abbott Laboratories, Acadia Pharmaceuticals, Alkermes Inc., American Cyanamid, Aspect Medical Systems, AstraZeneca, Avanir Pharmaceuticals, AXSOME Therapeutics, BioResearch, Braincells Inc., Bristol-Myers Squibb, CeNeRx BioPharma, Cephalon, Cerecor, Clintara LLC, Covance, Covidien, Eli Lilly and Company, EnVivo Pharmaceuticals Inc., Euthymics Bioscience Inc., Forest Pharmaceuticals Inc., FORUM Pharmaceuticals, Ganeden Biotech Inc., GlaxoSmithKline, Harvard 
Clinical Research Institute, Hoffman-LaRoche, Icon Clinical Research, i3 lnnovus/Ingenix, Janssen R\&D LLC, Jed Foundation, Johnson \& Johnson Pharmaceutical Research \& Development, Lichtwer Pharma GmbH, Lorex Pharmaceuticals, Lundbeck Inc., MedAvante, Methylation Sciences Inc., National Alliance for Research on Schizophrenia and Depression (NARSAD), National Center for Complementary and Alternative Medicine (NCCAM), National Coordinating Center for Integrated Medicine (NiiCM), National Institute of Drug Abuse (NIDA), National Institute of Mental Health (NIMH), Neuralstem Inc., NeuroRx, Novartis AG, Organon Pharmaceuticals, PamLab LLC, Pfizer Inc., Pharmacia \& Upjohn Company LLC, Pharmaceutical Research Associates Inc., Pharmavite ${ }^{\circledR}$ LLC, PharmoRx Therapeutics, Photothera, Reckitt Benckiser, RCT Logic LLC (formerly Clinical Trials Solutions LLC), Roche Pharmaceuticals, Sanofi-Aventis US LLC, Shire, Solvay Pharmaceuticals Inc., Stanley Medical Research Institute (SMRI), Synthelabo, Takeda Pharmaceuticals, Tal Medical, VistaGen, Wyeth-Ayerst Laboratories Advisory Board. Consultant: Abbott Laboratories, Acadia, Affectis Pharmaceuticals AG, Alkermes Inc., Amarin Pharma Inc., Aspect Medical Systems, AstraZeneca, Auspex Pharmaceuticals, Avanir Pharmaceuticals, AXSOME Therapeutics, Bayer AG, Best Practice Project Management Inc., Biogen, BioMarin Pharmaceuticals Inc., Biovail Corporation, BrainCells Inc., Bristol-Myers Squibb, CeNeRx BioPharma, Cephalon Inc., Cerecor, CNS Response Inc., Compellis Pharmaceuticals, Cypress Pharmaceutical Inc., DiagnoSearch Life Sciences (P) Ltd ., Dinippon Sumitomo Pharma Co. Inc., Dov Pharmaceuticals Inc., Edgemont Pharmaceuticals Inc., Eisai Inc., Eli Lilly and Company, EnVivo Pharmaceuticals Inc., ePharmaSolutions, EPIX Pharmaceuticals Inc., Euthymics Bioscience Inc., Fabre-Kramer Pharmaceuticals Inc., Forest Pharmaceuticals Inc., Forum Pharmaceuticals, GenOmind LLC, GlaxoSmithKline, Grunenthal $\mathrm{GmbH}$, Indivior, i3 lnnovus/Ingenis, Intracellular, Janssen Pharmaceutica, Jazz Pharmaceuticals Inc., Johnson \& Johnson Pharmaceutical Research \& Development LLC, Knoll Pharmaceuticals Corp., Labopharm Inc., Lorex Pharmaceuticals, Lundbeck Inc., MedAvante Inc., Merck \& Co. Inc., MSI Methylation Sciences Inc., Naurex Inc., Nestlé Health Sciences, Neuralstem Inc., Neuronetics Inc., NextWave Pharmaceuticals, Novartis AG, Nutrition 21, Orexigen Therapeutics Inc., Organon Pharmaceuticals, Osmotica, Otsuka Pharmaceuticals, Pamlab LLC, Pfizer Inc., PharmaStar, Pharmavite ${ }^{\circledR}$ LLC, PharmoRx Therapeutics, Precision Human Biolaboratory, Prexa Pharmaceuticals Inc., PPD, Puretech Ventures, PsychoGenics, Psylin Neurosciences Inc., RCT Logic LLC (formerly Clinical Trials Solutions LLC), Rexahn Pharmaceuticals Inc., Ridge Diagnostics Inc., Roche, SanofiAventis US LLC, Sepracor Inc., Servier Laboratories,
Schering-Plough Corporation, Shenox Pharmaceuticals, Solvay Pharmaceuticals Inc., Somaxon Pharmaceuticals Inc., Somerset Pharmaceuticals Inc., Sunovion Pharmaceuticals, Supernus Pharmaceuticals Inc., Synthelabo, Taisho Pharmaceutical Company, Takeda Pharmaceutical Company Limited, Tai Medical Inc., Tetragenex Pharmaceuticals Inc., TransForm Pharmaceuticals Inc., Transcept Pharmaceuticals Inc., Vanda Pharmaceuticals Inc. VistaGen. Speaking/Publishing: Adamed Co. Advanced Meeting Partners, American Psychiatric Association, American Society of Clinical Psychopharmacology, AstraZeneca, Belvoir Media Group, Boehringer lngelheim GmbH, Bristol-Myers Squibb, Cephalon Inc., CME Institute/Physicians Postgraduate Press Inc., Eli Lilly and Company, Forest Pharmaceuticals Inc., GlaxoSmithKline, Imedex LLC, MGH Psychiatry Academy/Primedia, MGH Psychiatry Academy/Reed Elsevier, Novartis AG, Organon Pharmaceuticals, Pfizer Inc., PharmaStar, United BioSource Corp., Wyeth-Ayerst Laboratories. Stock/Other Financial Options: Equity Holdings: Compellis, PsyBrain Inc. Royalty/Patent other income: patents for Sequential Parallel Comparison Design (SPCD), licensed by MGH to Pharmaceutical Product Development LLC (PPD), and patent application for a combination of Ketamine plus Scopolamine in Major Depressive Disorder (MOD), licensed by MGH to Biohaven. Copyright for the MGH Cognitive \& Physical Functioning Questionnaire (CPFQ), Sexual Functioning Inventory (SFI), Antidepressant Treatment Response Questionnaire (ATRQ), Discontinuation-Emergent Signs \& Symptoms (DESS), Symptoms of Depression Questionnaire (SDQ), and SAFER; Lippincott, Williams \& Wilkins; Wolters Kluwer; World Scientific Publishing Co. Pte. Ltd.

Joseph Goldberg has the following disclosures. Merck: speakers bureau, speaker's fee. Sunovion: speakers bureau and consultant, speaker's fee and consulting fee. Supernus: speakers bureau and consultant, speaker's fee and consulting fee. Medscape: consultant consulting fee. WebMD: consultant, consulting fee. Otsuka: speakers bureau and consultant, speaker's fee and consulting fee. Vanda Pharmaceuticals: speakers bureau, speaker's fee. WebMD: consultant, consulting fee.

Paul Keck has the following disclosures. Otsuke: advisory board, personal fees. Shire: advisory board, personal fees.

Yena Lee has nothing to disclose.

Gin Malhi reports grants from NHMRC, personal fees from Astrazeneca, personal fees from Lundbeck, personal fees from Janssen-Cilag, personal fees from Servier, other from Melbourne University, personal fees from Elsevier, grants from Ramsay Research and Teaching Fund, grants from American Foundation for Suicide Prevention, grants from Australian Rotary Health, outside the submitted work.

Ciro Marangoni has nothing to disclose. 
Susan McElroy reports personal fees from Bracket, personal fees from F. Hoffmann-La Roche Ltd., personal fees from MedAvante, personal fees from Mitsubishi Tanabe Pharma America, grants and personal fees from Myriad, grants and personal fees from Naurex, grants and personal fees from Novo Nordisk, grants and personal fees from Shire, grants and personal fees from Sunovion, grants from Alkermes, grants from Forest, grants from Marriott Foundation, grants from National Institute of Mental Health, grants from Takeda Pharmaceutical Company Ltd., outside the submitted work.

Roger McIntyre has the following disclosures. Advisory Boards: Lundbeck, Pfizer, AstraZeneca, Elli-Lilly, JanssenOrtho, Purdue, Johnson \& Johnson, Moksha8, Sunovion, Mitsubishi, Takeda, Forest, Otsuka, BristolMyers Squibb. Speakers Fees: Lundbeck, Pfizer, AstraZeneca, Elli-Lilly, JanssenOrtho, Purdue, Johnson \& Johnson, Moksha8, Sunovion, Mitsubishi, Takeda, Forest, Otsuka, Bristol-Myers Squibb. Research Grants: Lundbeck, JanssenOrtho, Shire, Purdue, AstraZeneca, Pfizer, Otsuka. Others: Allergan: research grants, patents. Shire: speaker's fees, profit-sharing agreements. Shire: advisory boards, speaker's fees, equity ownerships. Shire: research profit-sharing agreements

Michael Ostacher reports personal fees from Otsuka, personal fees from Eli Lilly, personal fees from Johnson \& Johnson, personal fees from Supernus Pharmaceuticals, personal fees from Sunovion Pharmaceuticals, personal fees from Lundbeck, personal fees from Acadia Pharmaceuticals, grants from Palo Alto Health Sciences, outside the submitted work.

Joshua Rosenblat has nothing to disclose.

Eva Solé has nothing to disclose.

Trisha Suppes reports grants from the National Institute of Mental Health, grants from the VA Cooperative Studies Program, grants from Pathways Genomics, grants from Stanley Medical Research Institute, personal fees from Medscape Education, personal fees from Global Medical Education, personal fees from CMEology, personal fees from Jones and Bartlett, personal fees from UpToDate, grants and personal fees from Sunovion Pharmaceuticals Inc., grants from Elan Pharma International Limited, personal fees from H. Lundbeck A/S, personal fees from AstraZeneca, personal fees from Merck \& Co., outside the submitted work.

Minoru Takeshima reports personal fees from Astellas, Eli Lilly, GlaxoSmithKline, Meiji Seika Pharma, Otsuka, Sumitomo Dainippon Pharma, and Yoshitomi, outside the submitted work.

Michael Thase has the following disclosures. Alkermes: personal fees, consultant. AstraZeneca: consultant, personal fees. Bristol-Myers Squibb Company: personal fees, consultant. Eli Lilly \& Company: grant, consultant, personal fees. Forest Laboratories: grant, consultant, personal fees. Gerson Lehman Group: consultant, grant, personal fees. GlaxoSmithKline: consultant, personal fees. Guidepoint Global: consultant, personal fees. H. Lundbeck A/S: consultant, personal fees. MedAvante: consultant; equity holdings, personal fees. Merck and Company: consultant, personal fees. Neuronetics Inc.: consultant, personal fees. Ortho-McNeil Pharmaceuticals: consultant, personal fees. Otsuka: consultant grant and personal fees. Pfizer: consultant, personal fees. Roche: consultant, personal fees. Shire US Inc.: consultant, personal fees. Sunovion Pharmaceuticals Inc.: consultant, personal fees. Takeda: consultant, personal fees. American Psychiatric Foundation: royalties. Guilford Publications: royalties. Herald House: royalties. W.W. Norton \& Company Inc.: royalties. Peloton Advantage: other spouse's employment (salary). Cerecor Inc.: consultant, personal fees. Moksha8: consultant, personal fees. Pamlab LLC (Nestlé): consultant, personal fees. Allergan: consultant, personal fees. Trius Therapeutical Inc.: consultant, personal fees. Fabre-Kramer Pharmaceuticals Inc.: consultant, personal fees.

Eduard Vieta has the following disclosures. Ab-Biotics: grant and personal fees. Acatis grant and personal fees. Allergen: grant and personal fees. AstraZeneca: grant and personal fees. Bristol-Myers Squibb: grant and personal fees. Ferrer: grant and personal fees. Forest Research Institute: grant and personal fees. Gedeon Richter: grant and personal fees. Glaxo-Smith Kline: grant and personal fees. Janssen: grant and personal fees. Lundbeck: grant and personal fees. Otsuka: grant and personal fees. Pfizer: grant and personal fees. Roche: grant and personal fees. Sanofi-Aventis: grant and personal fees. Servier: grant and personal fees. Sunovion: grant and personal fees. Takeda: grant and personal fees. Telefónica: grant and personal fees. The Brain and Behaviour Foundation: grant. The Spanish Ministry of Science and Innovation (CIBERSAM), grant. The Stanley Medical Research Institute, grant.

Allan Young has the following disclosures. Sunovion: personal fees. Lundbeck: personal fees. Eli Lilly: personal fees. AstraZeneca: personal fees. Livanova: personal fees. Jansen: grant.

Mark Zimmerman has nothing to disclose.

\section{REFERENCES:}

1. American Psychiatric Association. Diagnostic and Statistical Manual of Mental Disorders, 5th ed. Washington, DC: American Psychiatric Association; 2013.

2. Benazzi F. Reviewing the diagnostic validity and utility of mixed depression (depressive mixed states). Eur Psychiatry. 2008; 23(1): 40-48; Epub ahead of print Aug 30, 2007.

3. Hu J, Mansur R, McIntyre RS. Mixed specifier for bipolar mania and depression: highlights of DSM-5 changes and implications for diagnosis and treatment in primary care. Prim Care Companion CNS Disord. 2014; 16(2): pii: PCC.13r01599. Epub ahead of print 
Apr 17. https://www.ncbi.nlm.nih.gov/pmc/articles/PMC411 6292/. Accessed January 29, 2017.

4. Sato T, Bottlender R, Sievers M, Schröter A, Kleindienst N, Möller HJ. Evaluating the inter-episode stability of depressive mixed states. J Affect Disord. 2004; 81(2): 103-113.

5. Vieta E, Valentí M. Mixed states in DSM-5: implications for clinical care, education, and research. J Affect Disord. 2013; 148(1): 28-36; Epub ahead of print Apr 2. http://www.jad-journal.com/ article/S0165-0327(13)00232-2/pdf. Accessed January 29, 2017.

6. Solé E, Garriga M, Valentí M, Vieta E. Mixed features in bipolar disorder. CNS Spectr. 2017: 1-7; Epub ahead of print.

7. Cerullo MA, Strakowski SM. A systematic review of the evidence for the treatment of acute depression in bipolar I disorder. CNS Spectr. 2013; 18(4): 199-208; Epub ahead of print Mar 18. https://www.ncbi.nlm.nih.gov/pmc/articles/PMC3688656/. Accessed January 29, 2017.

8. Cleare A, Pariante CM, Young AH, et al. Evidence-based guidelines for treating depressive disorders with antidepressants: a revision of the 2008 British Association for Psychopharmacology guidelines. J Psychopharmacol. 2015. 29(5): 459-525; Epub ahead of print May 12. http://journals.sagepub.com/doi/pdf/ 10.1177/0269881115581093. Accessed January 29, 2017

9. Connolly KR, Thase ME. The clinical management of bipolar disorder: a review of evidence-based guidelines. Prim Care Companion CNS Disord. 2011; 13(4): pii: PCC.10r01097. https://www.ncbi.nlm.nih.gov/pmc/articles/PMC3219517/. Accessed January 29, 2017.

10. Fountoulakis KN, Kontis D, Gonda X, Siamouli M, Yatham LN. Treatment of mixed bipolar states. Int J Neuropsychopharmacol. 2012; 15(7): 1015-1026; Epub ahead of print Jan 5. https://academic.oup.com/ijnp/article-lookup/doi/10.1017/ S1461145711001817. Accessed January 29, 2017.

11. Goodwin GM, Consensus Group of the British Association for Psychopharmacology. Evidence-based guidelines for treating bipolar disorder: revised second edition. Recommendations from the British Association for Psychopharmacology.

J Psychopharmacol. 2009; 23(4): 346-388; Epub ahead of print Mar 27. http://journals.sagepub.com/doi/pdf/ 10.1177/0269881109102919. Accessed January 29, 2017.

12. Grunze H, Vieta E, Goodwin GM, et al. The World Federation of Societies of Biological Psychiatry (WFSBP) Guidelines for the Biological Treatment of Bipolar Disorders: update 2010 on the treatment of acute bipolar depression. World J Biol Psychiatry. 2010; 11(2): 81-109.

13. McIntyre RS, Yoon J. Efficacy of antimanic treatments in mixed states. Bipolar Disord. 2012; 14(Suppl. 2): 22-36.

14. Musetti L, Del Grande C, Marazziti D, Dell'Osso L. Treatment of bipolar depression. CNS Spectr. 2013; 18(4): 177-187; Epub ahead of print Feb 8.

15. Nivoli AM, Murru A, Goikolea JM, et al. New treatment guidelines for acute bipolar mania: a critical review. J Affect Disord. 2012; 140(2): 125-141; Epub ahead of print Nov 17, 2011.

16. Woo YS, Lee JG, Jeong JH, et al. Korean Medication Algorithm Project for Bipolar Disorder, third revision. Neuropsychiatr Dis Treat. 2015; 11: 493-506; https://www.ncbi.nlm.nih.gov/pmc/ articles/PMC4348143/. Accessed January 29, 2017.

17. Yatham LN, Kennedy SH, Parikh SV, et al. Canadian Network for Mood and Anxiety Treatments (CANMAT) and International Society for Bipolar Disorders (ISBD) collaborative update of CANMAT guidelines for the management of patients with bipolar disorder: update 2013. Bipolar Disord. 2013; 15(1): 1-44; Epub ahead of print Dec 12, 2012.

18. Yatham LN, Kennedy SH, Schaffer A, et al. Canadian Network for Mood and Anxiety Treatments (CANMAT) and International Society for Bipolar Disorders (ISBD) collaborative update of
CANMAT guidelines for the management of patients with bipolar disorder: update 2009. Bipolar Disord. 2009; 11(3): 225-255.

19. Fountoulakis KN, Grunze H, Vieta E, et al. The International College of Neuro-Psychopharmacology (CINP) treatment guidelines for bipolar disorder in adults (CINP-BD-2017), part 3: the clinical guidelines. Int J Neuropsychopharmacol. 2016: pii: pyw109. Epub ahead of print. https://academic.oup.com/ ijnp/article-lookup/doi/10.1093/ijnp/pyw109. Accessed January $29,2017$.

20. Grunze H, Azorin JM. Clinical decision making in the treatment of mixed states. World J Biol Psychiatry. 2014; 15(5): 355-368; Epub ahead of print May 14.

21. Takeshima M, Oka T. DSM-5-defined "mixed features" and Benazzi's mixed depression: which is practically useful to discriminate bipolar disorder from unipolar depression in patients with depression? Psychiatry Clin Neurosci. 2015; 69(2): 109-116; Epub ahead of print Jul 14, 2014. http://onlinelibrary. wiley.com/doi/10.1111/pcn.12213/full. Accessed January 29 , 2017.

22. Koukopoulos A, Sani G. DSM-5 criteria for depression with mixed features: a farewell to mixed depression. Acta Psychiatr Scand. 2014; 129(1): 4-16; Epub ahead of print Apr 19, 2013.

23. Malhi GS, Lampe L, Coulston CM, et al. Mixed state discrimination: a DSM problem that wont go away? J Affect Disord. 2014; 158: 8-10; Epub ahead of print Jan 28.

24. Benazzi F, Akiskal HS. Psychometric delineation of the most discriminant symptoms of depressive mixed states. Psychiatry Res. 2006; 141(1): 81-88; Epub ahead of print Nov 28, 2005.

25. Faedda GL, Marangoni C, Reginaldi D. Depressive mixed states: a reappraisal of Koukopoulos' criteria. J Affect Disord. 2015; 176: 18-23; Epub ahead of print Feb 4.

26. Goldberg JF, Perlis RH, Bowden CL, et al. Manic symptoms during depressive episodes in 1,380 patients with bipolar disorder: findings from the STEP-BD. Am J Psychiatry. 2009; 166(2): 173-181; Epub ahead of print Jan 2. http://ajp.psychiatryonline. org/doi/pdf/10.1176/appi.ajp.2008.08050746. Accessed January $29,2017$.

27. Olgiati P, Serretti A, Colombo C. Retrospective analysis of psychomotor agitation, hypomanic symptoms, and suicidal ideation in unipolar depression. Depress Anxiety. 2006; 23(7): 389-397.

28. Maj M. "Mixed" depression: drawbacks of DSM-5 (and other) polythetic diagnostic criteria. J Clin Psychiatry. 2015; 76(3): e381-e382; http://www.psychiatrist.com/jcp/article/Pages/ 2015/v76n03/v76n0324.aspx. Accessed January 29, 2017.

29. Perugi G, Angst J, Azorin JM, et al. Mixed features in patients with a major depressive episode: the BRIDGE-II-MIX study. J Clin Psychiatry. 2015; 76(3): e351-e358.

30. Sani G, Napoletano F, Vohringer PA, et al. Mixed depression: clinical features and predictors of its onset associated with antidepressant use. Psychother Psychosom. . 2014; 83(4): 213-221; Epub ahead of print Jun 19.

31. Sani G, Vohringer PA, Napoletano F, et al. Koukopoulos' diagnostic criteria for mixed depression: a validation study. J Affect Disord. 2014; 164: 14-18; Epub ahead of print Apr 12.

32. Goldberg JF. Mixed depression: a farewell to differential diagnosis? J Clin Psychiatry. 2015; 76(3): e378-e380; http://www. psychiatrist.com/jcp/article/Pages/2015/v76n03/v76n0323. aspx. Accessed January 30, 2017.

33. Prieto ML, Youngstrom EA, Ozerdem A, et al. Different patterns of manic/hypomanic symptoms in depression: a pilot modification of the Hypomania Checklist-32 to assess mixed depression. J Affect Disord. 2015; 172: 355-360. 
34. Axelson D, Goldstein B, Goldstein T, et al. Diagnostic precursors to bipolar disorder in offspring of parents with bipolar disorder: a longitudinal study. Am J Psychiatry. 2015; 172(7): 638-646;

Epub ahead of print Mar 3. https://www.ncbi.nlm.nih.gov/pmc/ articles/PMC4489996/. Accessed January 30, 2017.

35. Akiskal HS, Benazzi F. Family history validation of the bipolar nature of depressive mixed states. J Affect Disord. 2003; 73(1-2): 113-122.

36. Brietzke E, Moreira CLRL, Duarte SVB, et al. Impact of comorbid migraine on the clinical course of bipolar disorder. Compr Psychiatry. 2012; 53(6): 809-812; Epub ahead of print Nov 20, 2011.

37. Oedegaard KJ, Fasmer OB. Is migraine in unipolar depressed patients a bipolar spectrum trait? J Affect Disord. 2005; 84(2-3): 233-242.

38. Ortiz A, Cervantes P, Zlotnik G, et al. Cross-prevalence of migraine and bipolar disorder. Bipolar Disord. 2010; 12(4): 397-403.

39. Jerrell JM, McIntyre RS, Tripathi A. A cohort study of the prevalence and impact of comorbid medical conditions in pediatric bipolar disorder. J Clin Psychiatry. 2010; 71(11): 1518-1525; Epub ahead of print Jun 15. http://www.psychiatrist.com/JCP/article/Pages/2010/ v71n11/v71n1115.aspx. Accessed January 30, 2017.

40. Angst J, Cui L, Swendsen J, et al. Major depressive disorder with subthreshold bipolarity in the National Comorbidity Survey Replication. Am J Psychiatry. 2010; 167(10): 1194-1201; Epub ahead of print Aug 16. https://www.ncbi.nlm.nih.gov/pmc/ articles/PMC3145248/pdf/nihms249007.pdf. Accessed January $30,2017$.

41. Dudek D, Siwek M, Zielinska D, Jaeschke R, Rybakowski J. Diagnostic conversions from major depressive disorder into bipolar disorder in an outpatient setting: results of a retrospective chart review. J Affect Disord. 2013; 144(1-2): 112-115; Epub ahead of print Aug 5, 2012.

42. Sharma V, Khan M, Smith A. A closer look at treatment-resistant depression: is it due to a bipolar diathesis? J Affect Disord. 2005; 84(2-3): 251-257.

43. Rihmer Z, Gonda X. Antidepressant-resistant depression and antidepressant-associated suicidal behaviour: the role of underlying bipolarity. Depress Res Treat. 2011; 2011: 906462. Epub ahead of print Apr 3. https://www.ncbi.nlm.nih.gov/pmc/ articles/PMC3096313/pdf/DRT2011-906462.pdf. Accessed January 30, 2017.

44. Amsterdam JD, Shults J. Does tachyphylaxis occur after repeated antidepressant exposure in patients with bipolar II major depressive episode? J Affect Disord. 2009; 115(1-2): 234-240; Epub ahead of print Aug 9, 2008.

45. Post RM, Leverich GS, Altshuler LL, et al. Relationship of prior antidepressant exposure to long-term prospective outcome in bipolar I disorder outpatients. J Clin Psychiatry. 2012; 73(7): 924-930; Epub ahead of print Mar 20.

46. Goldberg JF, Garno JL, Callahan AM, Kearns DL, Kerner B, Ackerman SH. Overdiagnosis of bipolar disorder among substance use disorder inpatients with mood instability. J Clin Psychiatry. 2008; 69(11): 1751-1757; Epub ahead of print Aug 12, 2008.

47. Galvao F, Sportiche S, Lambert J, et al. Clinical differences between unipolar and bipolar depression: interest of BDRS (Bipolar Depression Rating Scale). Compr Psychiatry. 2013; 54(6): 605-610; Epub ahead of print Jan 31.

48. Williams JB, Terman M, Link MJ, Amira L, Rosenthal NE. Hypomania interview guide (including hyperthymia): retrospective assessment version (HIGH-R). Depress Anxiety. 1999; 9(2): 92-100.

49. Benazzi F. Depressive mixed state: dimensional versus categorical definitions. Prog Neuropsychopharmacol Biol Psychiatry. 2003; 27(1): 129-134.
50. Hergueta T, Weiller E. Evaluating depressive symptoms in hypomanic and manic episodes using a structured diagnostic tool: validation of a new Mini International Neuropsychiatric Interview (M.I.N.I.) module for the DSM-5 "With Mixed Features" specifier. Int J Bipolar Disord. 2013; 1: 21. https://www.ncbi.nlm.nih.gov/ pmc/articles/PMC4230688/. Accessed January 30, 2017.

51. Zimmerman M, Chelminski I, Young D, Dalrymple K, Martinez JH. A clinically useful self-report measure of the DSM-5 mixed features specifier of major depressive disorder. J Affect Disord. 2014; 168: 357-362; Epub ahead of print Jul 22.

52. Altinbas K, Ozerdem A, Prieto ML, et al. A multinational study to pilot the modified Hypomania Checklist (mHCL) in the assessment of mixed depression. J Affect Disord. 2014; 152-154: 478-482.

53. Hirschfeld RM, Williams JB, Spitzer RL, et al. Development and validation of a screening instrument for bipolar spectrum disorder: the Mood Disorder Questionnaire. Am J Psychiatry. 2000; 157(11): 1873-1875; http://ajp.psychiatryonline.org/doi/pdf/ 10.1176/appi.ajp.157.11.1873. Accessed January 30, 2017.

54. Altman EG, Hedeker D, Peterson JL, Davis JM. The Altman Self-Rating Mania Scale. Biol Psychiatry. 1997; 42(10): 948-955.

55. Akiskal HS, Benazzi F, Perugi G, Rihmer Z. Agitated "unipolar" depression re-conceptualized as a depressive mixed state: implications for the antidepressant-suicide controversy. J Affect Disord. 2005; 85(3): 245-258.

56. Ng F, Mammen OK, Wilting I, et al. The International Society for Bipolar Disorders (ISBD) consensus guidelines for the safety monitoring of bipolar disorder treatments. Bipolar Disord. 2009; 11(6): 559-595; http://onlinelibrary.wiley.com/doi/10.1111/ j.1399-5618.2009.00737.x/full. Accessed January 30, 2017.

57. Akiskal HS, Benazzi F. Psychopathologic correlates of suicidal ideation in major depressive outpatients: is it all due to unrecognized (bipolar) depressive mixed states? Psychopathology. $2005 ; \mathbf{3 8}(5)$ : 273-280.

58. Angst J, Azorin JM, Bowden CL, et al. Prevalence and characteristics of undiagnosed bipolar disorders in patients with a major depressive episode: the BRIDGE Study. Arch Gen Psychiatry. 2011; 68(8): 791-798; http://jamanetwork.com/ journals/jamapsychiatry/fullarticle/1107421. Accessed January $30,2017$.

59. Balazs J, Benazzi F, Rihmer Z, Rihmer A, Akiskal KK, Akiskal HS. The close link between suicide attempts and mixed (bipolar) depression: implications for suicide prevention. J Affect Disord. 2006; 91(2-3): 133-138; Epub ahead of print Feb 3.

60. Benazzi F, Berk M, Frye MA, Wang W, Barraco A, Tohen M. Olanzapine/fluoxetine combination for the treatment of mixed depression in bipolar I disorder: a post-hoc analysis. J Clin Psychiatry. 2009; 70(10): 1424-1431; http://www.psychiatrist. com/JCP/article/Pages/2009/v70n10/v70n1011.aspx. Accessed January 30, 2017.

61. Benazzi F. Bipolar disorder: focus on bipolar II disorder and mixed depression. Lancet. 2007; 369(9565): 935-945.

62. Bjorklund L, Horsdal HT, Mors O, Ostergaard SD, Gasse C. Trends in the psychopharmacological treatment of bipolar disorder: a nationwide register-based study. Acta Neuropsychiatr. 2016; 28(2): 75-84; Epub ahead of print Sep 11, 2015.

63. Gijsman HJ, Geddes JR, Rendell JM, Nolen WA, Goodwin GM. Antidepressants for bipolar depression: a systematic review of randomized, controlled trials. Am J Psychiatry. 2004; 161(9): 1537-1547; https://www.ncbi.nlm.nih.gov/pubmedhealth/ PMH0021171/. Accessed January 30, 2017.

64. Frye MA, Helleman G, McElroy SL, et al. Correlates of treatmentemergent mania associated with antidepressant treatment in bipolar depression. Am J Psychiatry. 2009; 166(2): 164-172; Epub ahead of print Nov 17, 2008. http://ajp.psychiatryonline.org/doi/ 
pdf/10.1176/appi.ajp.2008.08030322. Accessed January 30 , 2017.

65. Möller HJ, Grunze H, Broich K. Do recent efficacy data on the drug treatment of acute bipolar depression support the position that drugs other than antidepressants are the treatment of choice? A conceptual review. Eur Arch Psychiatry Clin Neurosci. 2006; 256(1): 1-16; Epub ahead of print Aug 4, 2005.

66. Nierenberg AA. An analysis of the efficacy of treatments for bipolar depression. J Clin Psychiatry. 2008; 69(Suppl. 5): 4-8

67. Pacchiarotti I, Bond DJ, Baldessarini RJ, et al. The International Society for Bipolar Disorders (ISBD) task force report on antidepressant use in bipolar disorders. Am J Psychiatry. 2013; 170(11): 1249-1262; https://www.ncbi.nlm.nih.gov/pmc/ articles/PMC4091043/. Accessed January 30, 2017.

68. Pae CU, Vohringer PA, Holtzman NS, et al. Mixed depression: a study of its phenomenology and relation to treatment response. J Affect Disord. 2012; 136(3): 1059-1061; Epub ahead of print Dec 14, 2011.

69. Patel R, Reiss P, Shetty H, et al. Do antidepressants increase the risk of mania and bipolar disorder in people with depression? A retrospective electronic case register cohort study. BMJ Open. 2015; 5(12): e008341. https://www.ncbi.nlm.nih.gov/pmc/ articles/PMC4679886/pdf/bmjopen-2015-008341.pdf. Accessed January 30, 2017.

70. Rihmer Z, Akiskal H. Do antidepressants t(h)reat(en) depressives? Toward a clinically judicious formulation of the antidepressantsuicidality FDA advisory in light of declining national suicide statistics from many countries. J Affect Disord. 2006; 94(1-3): 3-13; Epub ahead of print May 19.

71. Fountoulakis KN, Kasper S, Andreassen O, et al. Efficacy of pharmacotherapy in bipolar disorder: a report by the WPA section on pharmacopsychiatry. Eur Arch Psychiatry Clin Neurosci. 2012 262(Suppl 1.): 1-48.

72. Sidor MM, Macqueen GM. Antidepressants for the acute treatment of bipolar depression: a systematic review and meta-analysis. J Clin Psychiatry. 2011; 72(2): 156-167; Epub ahead of print Oct 5, 2010. https://www.ncbi.nlm.nih.gov/pubmedhealth/ PMH0031744/. Accessed January 30, 2017.

73. Tundo A, Calabrese JR, Proietti L, de Filippis R. Short-term antidepressant treatment of bipolar depression: are ISBD recommendations useful in clinical practice? J Affect Disord. 2015; 171: 155-160; Epub ahead of print Sep $28,2014$.

74. Grunze H. The role of polypharmacy in bipolar disorder treatment guidelines. In: Ritsner MS, ed. Polypharmacy in Psychiatry Practice Vol. II: Use of Polypharmacy in the "Real World." New York: Springer Science; 2013: P. 275-287.

75. Heijnen WT, De Fruyt J, Wierdsma AI, Sienaert P, Birkenhager TK. Efficacy of tranylcypromine in bipolar depression: a systematic review. J Clin Psychopharmacol. 2015; 35(6): 700-705.

76. Berk M, Tiller JW, Zhao J, Yatham LN, Malhi GS, Weiller E. Effects of asenapine in bipolar I patients meeting proxy criteria for moderate to severe mixed major depressive episodes: a post-hoc analysis. J Clin Psychiatry. 2015; 76(6): 728-734; http://www. psychiatrist.com/jcp/article/Pages/2015/v76n06/v76n0607. aspx. Accessed January 30, 2017

77. McIntyre RS, Tohen M, Berk M, Zhao J, Weiller E. DSM-5 mixed specifier for manic episodes: evaluating the effect of depressive features on severity and treatment outcome using asenapine clinical trial data. J Affect Disord. 2013; 150(2): 378-383; Epub ahead of print May 25

78. McIntyre RS, Cucchiaro J, Pikalov A, Kroger H, Loebel A. Lurasidone in the treatment of bipolar depression with mixed (subsyndromal hypomanic) features: post hoc analysis of a randomized placebo-controlled trial. J Clin Psychiatry. 2015;
76(4): 398-405; http://www.psychiatrist.com/jcp/article/Pages/ 2015/v76n04/v76n0402.aspx. Accessed January 30, 2017.

79. Suppes T, Silva R, Cucchiaro J, et al. Lurasidone for the treatment of major depressive disorder with mixed features: a randomized, double-blind, placebo-controlled study. Am J Psychiatry. 2016; 173(4): 400-407; Epub ahead of print Nov 10, 2015.

80. Tohen M, Kanba S, McIntyre RS, Fujikoshi S, Katagiri H. Efficacy of olanzapine monotherapy in the treatment of bipolar depression with mixed features. J Affect Disord. 2014; 164: 57-62; Epub ahead of print Jul 3 .

81. Suppes T, Ketter TA, Gwizdowski IS, et al. First controlled treatment trial of bipolar II hypomania with mixed symptoms: quetiapine versus placebo. J Affect Disord. 2013; 150(1): 37-43; Epub ahead of print Mar 19.

82. Patkar A, Gilmer W, Pae CU, et al. A 6-week randomized double-blind placebo-controlled trial of ziprasidone for the acute depressive mixed state. PLoS One. 2012; 7(4): e34757. Epub ahead of print Apr 24. https://www.ncbi.nlm.nih. gov/pmc/articles/PMC3335844/. Accessed January 30, 2017

83. Lombardo I, Sachs G, Kolluri S, Kremer C, Yang R. Two 6-week, randomized, double-blind, placebo-controlled studies of ziprasidone in outpatients with bipolar I depression: did baseline characteristics impact trial outcome? J Clin Psychopharmacol. 2012; 32(4): 470-478.

84. Takeshima M. Treating mixed mania/hypomania: a review and synthesis of the evidence. CNS Spectr. 2016: 1-9; Epub ahead of print.

85. Kelly T, Lieberman DZ. The utility of low-dose aripiprazole for the treatment of bipolar II and bipolar NOS depression. J Clin Psychopharmacol. 2017; 37(1): 99-101.

86. Stahl SM. Prescriber's Guide: Stahl's Essential Psychopharmacology, 5th ed. New York: Cambridge University Press; 2014.

87. Swann AC, Bowden CL, Morris D, et al. Depression during mania: treatment response to lithium or divalproex. Arch Gen Psychiatry. 1997; 54(1): 37-42.

88. Magiria S. Evidence-based combination therapy for bipolar disorder. In: Ritsner MS, ed. Polypharmacy in Psychiatry Practice Vol. II: Use of Polypharmacy in the "Real World." New York, NY: Springer Science; 2013: P. 159-177.

89. Goldberg JF, Perlis RH, Ghaemi SN, et al. Adjunctive antidepressant use and symptomatic recovery among bipolar depressed patients with concomitant manic symptoms: findings from the STEP-BD. Am J Psychiatry. 2007; 164(9): 1348-1355; http://ajp.psychiatryonline.org/doi/pdf/10.1176/appi. ajp.2007.05122032. Accessed January 30, 2017.

90. Ei-Mallakh RS, Karippot A. Antidepressant-associated chronic irritable dysphoria (acid) in bipolar disorder: a case series. J Affect Disord. 2005; 84(2-3): 267-272.

91. Altshuler LL, Post RM, Hellemann G, et al. Impact of antidepressant continuation after acute positive or partial treatment response for bipolar depression: a blinded, randomized study. J Clin Psychiatry. 2009; 70(4): 450-457; Epub ahead of print Apr 7.

92. Bauer M, Berman S, Stamm T, et al. Levothyroxine effects on depressive symptoms and limbic glucose metabolism in bipolar disorder: a randomized, placebo-controlled positron emission tomography study. Mol Psychiatry. 2016; 21(2): 229-236; Epub ahead of print Jan 20, 2015. https://www.ncbi.nlm.nih.gov/pmc/ articles/PMC4790155/. Accessed January 30, 2017.

93. Stamm TJ, Lewitzka U, Sauer C, et al. Supraphysiologic doses of levothyroxine as adjunctive therapy in bipolar depression: a randomized, double-blind, placebo-controlled study. J Clin Psychiatry. 2014; 75(2): 162-168. 
94. Fernandes BS, Dean OM, Dodd S, Malhi GS, Berk M $\mathrm{N}$-acetylcysteine in depressive symptoms and functionality: a systematic review and meta-analysis. J Clin Psychiatry. 2016; 77(4): e457-e466.

95. Berk M, Dean O, Cotton SM, et al. The efficacy of N-acetylcysteine as an adjunctive treatment in bipolar depression: an open label trial. J Affect Disord. 2011; 135(1-3): 389-394; Epub ahead of print Jun 29.

96. Sarris J, Mischoulon D, Schweitzer I. Omega-3 for bipolar disorder: meta-analyses of use in mania and bipolar depression. J Clin Psychiatry. 2012; 73(1): 81-86; Epub ahead of print Aug 9, 2011.

97. Geoffroy PA, Etain B, Franchi JA, Bellivier F, Ritter P. Melatonin and melatonin agonists as adjunctive treatments in bipolar disorders. Curr Pharm Des. 2015; 21 (23): 3352-3358.

98. Faridhosseini F, Sadeghi R, Farid L, Pourgholami M. Celecoxib: a new augmentation strategy for depressive mood episodes. A systematic review and meta-analysis of randomized placebocontrolled trials. Hum Psychopharmacol. 2014; 29(3): 216-223; Epub ahead of print Mar 16.

99. Corp SA, Gitlin MJ, Altshuler LL. A review of the use of stimulants and stimulant alternatives in treating bipolar depression and major depressive disorder. J Clin Psychiatry. 2014; 75(9): 1010-1018.

100. Goss AJ, Kaser M, Costafreda SG, Sahakian BJ, Fu CH. Modafinil augmentation therapy in unipolar and bipolar depression: a systematic review and meta-analysis of randomized controlled trials. J Clin Psychiatry. 2013; 74(11): 1101-1107; https://www.ncbi.nlm.nih.gov/pubmedhealth/PMH0061792/. Accessed January 30, 2017.

101. Taylor MJ, Wilder H, Bhagwagar Z, Geddes J. Inositol for depressive disorders. Cochrane Database Syst Rev. 2004; 2: CD004049.

102. Mukai T, Kishi T, Matsuda Y, Iwata N. A meta-analysis of inositol for depression and anxiety disorders. Hum Psychopharmacol. 2014; 29(1): 55-63; Epub ahead of print Dec 3, 2013.

103. Kraus C, Rabl U, Vanicek T, et al. Administration of ketamine for unipolar and bipolar depression. Int J Psychiatry Clin Pract. 2017: 1-12; Epub ahead of print.
104. McCloud TL, Caddy C, Jochim J, et al. Ketamine and other glutamate receptor modulators for depression in bipolar disorder in adults. Cochrane Database Syst Rev. 2015; 9: CD011611.

http://onlinelibrary.wiley.com/doi/10.1002/14651858. CD011611.pub2/abstract. Accessed January 30, 2017.

105. Dell'Osso B, Ketter TA. Assessing efficacy/effectiveness and safety/tolerability profiles of adjunctive pramipexole in bipolar depression: acute versus long-term data. Int Clin Psychopharmacol. 2013; 28(6): 297-304.

106. Muneer A. Pharmacotherapy of bipolar disorder with quetiapine: a recent literature review and an update. Clin Psychopharmacol Neurosci. 2015; 13(1): 25-35; https://www.ncbi.nlm.nih.gov/ pmc/articles/PMC4423161/pdf/cpn-13-25.pdf. Accessed January 30, 2017.

107. Dilsaver SC, Benazzi F, Akiskal HS. Mixed states: the most common outpatient presentation of bipolar depressed adolescents? Psychopathology. 2005; 38(5): 268-272; Epub ahead of print Sep 21.

108. Dilsaver SC, Benazzi F, Rihmer Z, Akiskal KK, Akiskal HS. Gender, suicidality and bipolar mixed states in adolescents. J Affect Disord. 2005; 87(1): 11-16.

109. Thapar A, Collishaw S, Pine DS, Thapar AK. Depression in adolescence. Lancet. 2012; 379(9820): 1056-1067; Epub ahead of print Feb 2. https://www.ncbi.nlm.nih.gov/pmc/articles/ PMC3488279/pdf/nihms415614.pdf. Accessed January $30,2017$.

110. Singh MK, Ketter T, Chang KD. Distinguishing bipolar disorder from other psychiatric disorders in children. Curr Psychiatry Rep. 2014; 16(12): 516

111. Cipriani A, Zhou X, Del Giovane C, et al. Comparative efficacy and tolerability of antidepressants for major depressive disorder in children and adolescents: a network meta-analysis. Lancet. 2016; 388(10047): 881-890; Epub ahead of print Jun 8.

112. Cohen LS, Wang B, Nonacs R, Viguera AC, Lemon EL, Freeman MP. Treatment of mood disorders during pregnancy and postpartum. Psychiatr Clin North Am. 2010; 33(2): 273-293. 